\title{
Family Medicine and
community Health Semistructured interviewing in primary care research: a balance of relationship and rigour
}

\author{
Melissa DeJonckheere, ${ }^{1}$ Lisa M Vaughn ${ }^{2,3}$
}

To cite: DeJonckheere M, Vaughn LM. Semistructured interviewing in primary care research: a balance of relationship and rigour. Fam Med Com Health 2019;7:e000057. doi:10.1136/ fmch-2018-000057

- Additional material is published online only. To view please visit the journal online (http://dx.doi.org/10.1136/fmch2018-000057).

Received 03 November 2018 Revised 04 December 2018 Accepted 23 January 2019

Check for updates

(C) Author(s) (or their employer(s)) 2019. Re-use permitted under CC BY-NC. No commercial re-use. See rights and permissions. Published by BMJ.

${ }^{1}$ Department of Family Medicine, University of Michigan, Ann Arbor, Michigan, USA

${ }^{2}$ Department of Pediatrics, University of Cincinnati College of Medicine, Cincinnati, Ohio, USA

${ }^{3}$ Division of Emergency Medicine, Cincinnati Children's Hospital Medical Center, Cincinnati, Ohio, USA

Correspondence to Dr Melissa DeJonckheere; mdejonck@med.umich.edu

\section{ABSTRACT}

Semistructured in-depth interviews are commonly used in qualitative research and are the most frequent qualitative data source in health services research. This method typically consists of a dialogue between researcher and participant, guided by a flexible interview protocol and supplemented by follow-up questions, probes and comments. The method allows the researcher to collect open-ended data, to explore participant thoughts, feelings and beliefs about a particular topic and to delve deeply into personal and sometimes sensitive issues. The purpose of this article was to identify and describe the essential skills to designing and conducting semistructured interviews in family medicine and primary care research settings. We reviewed the literature on semistructured interviewing to identify key skills and components for using this method in family medicine and primary care research settings. Overall, semistructured interviewing requires both a relational focus and practice in the skills of facilitation. Skills include: (1) determining the purpose and scope of the study; (2) identifying participants; (3) considering ethical issues; (4) planning logistical aspects; (5) developing the interview guide; (6) establishing trust and rapport; (7) conducting the interview; (8) memoing and reflection; (9) analysing the data; (10) demonstrating the trustworthiness of the research; and (11) presenting findings in a paper or report. Semistructured interviews provide an effective and feasible research method for family physicians to conduct in primary care research settings. Researchers using semistructured interviews for data collection should take on a relational focus and consider the skills of interviewing to ensure quality. Semistructured interviewing can be a powerful tool for family physicians, primary care providers and other health services researchers to use to understand the thoughts, beliefs and experiences of individuals. Despite the utility, semistructured interviews can be intimidating and challenging for researchers not familiar with qualitative approaches. In order to elucidate this method, we provide practical guidance for researchers, including novice researchers and those with few resources, to use semistructured interviewing as a data collection strategy. We provide recommendations for the essential steps to follow in order to best implement semistructured interviews in family medicine and primary care research settings.

\section{INTRODUCTION}

Semistructured interviews can be used by family medicine researchers in clinical settings or academic settings even with few resources.
In contrast to large-scale epidemiological studies, or even surveys, a family medicine researcher can conduct a highly meaningful project with interviews with as few as 8-12 participants. For example, Chang and her colleagues, all family physicians, conducted semistructured interviews with 10 providers to understand their perspectives on weight gain in pregnant patients. ${ }^{1}$ The interviewers asked questions about providers' overall perceptions on weight gain, their clinical approach to weight gain during pregnancy and challenges when managing weight gain among pregnant patients. Additional examples conducted by or with family physicians or in primary care settings are summarised in table $1 .{ }^{1-6}$

From our perspective as seasoned qualitative researchers, conducting effective semistructured interviews requires: (1) a relational focus, including active engagement and curiosity, and (2) practice in the skills of interviewing. First, a relational focus emphasises the unique relationship between interviewer and interviewee. To obtain quality data, interviews should not be conducted with a transactional question-answer approach but rather should be unfolding, iterative interactions between the interviewer and interviewee. Second, interview skills can be learnt. Some of us will naturally be more comfortable and skilful at conducting interviews but all aspects of interviews are learnable and through practice and feedback will improve. Throughout this article, we highlight strategies to balance relationship and rigour when conducting semistructured interviews in primary care and the healthcare setting.

\section{BACKGROUND}

Qualitative research interviews are 'attempts to understand the world from the subjects' point of view, to unfold the meaning of peoples' experiences, to uncover their lived world prior to scientific explanations' (p 1). ${ }^{7}$ 
Table 1 Examples of research articles using semistructured interviews in primary care research

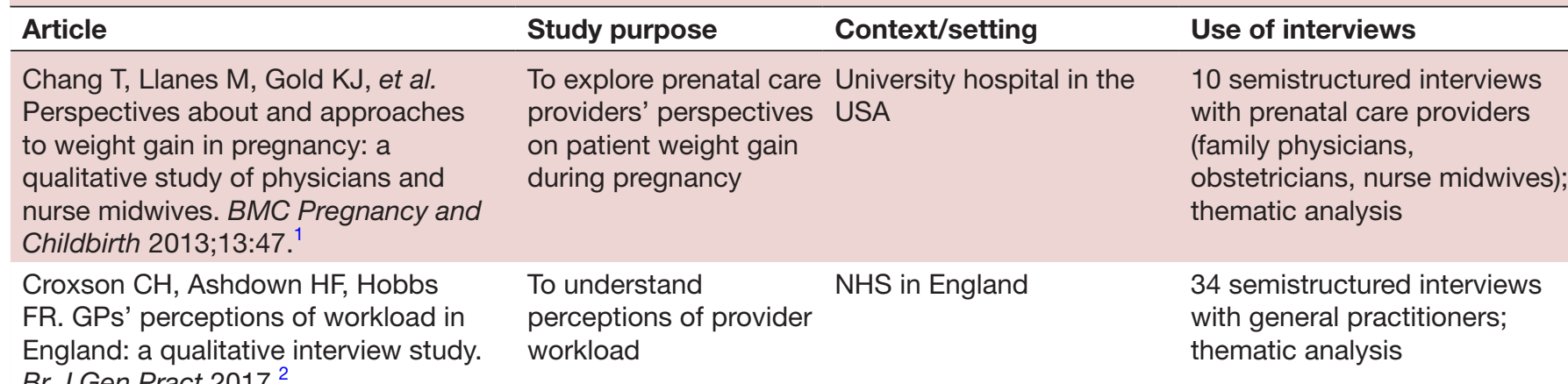

\section{DeJonckheere $\mathrm{M}$, Robinson $\mathrm{CH}$, Evans} $\mathrm{L}$, et al. Designing for clinical change: creating an intervention to implement new statin guidelines in a primary care clinic. JMIR Human Factors $2018 ; 5^{3}$.

Griffiths F, Lowe P, Boardman F, et al. Becoming pregnant: exploring the perspectives of women living with diabetes. Br J Gen Pract 2008;58:184$90^{4}$.

Saigal P, Takemura Y, Nishiue T, et al. Factors considered by medical students when formulating their specialty preferences in Japan: findings from a qualitative study BMC Med Educ 7:31, 2007. 5

Schoenborn NL, Lee K, Pollack CE, et al. Older adults' preferences for when and how to discuss life expectancy in primary care. The Journal of the American Board of Family Medicine $2017 ; 30: 813-5 .^{6}$
To elicit provider perspectives of their uptake of new statin guidelines.

To tailor a local quality improvement intervention to improve statin prescribing.

To explore women's accounts of their journeys to becoming pregnant while living with type 1 diabetes

\section{To understand}

factors considered by Japanese medical students when

choosing their specialty

\section{To elucidate}

perspectives on how and when to discuss life expectancy with older adults

\section{Veterans Affairs Medical}

Center in the USA

\section{5 semistructured interviews with providers (primary care physicians and clinical pharmacists); deductive thematic analysis}

\section{Four UK specialist diabetes 15 semistructured} antenatal clinics

\section{interviews with women with} pregestational type 1 diabetes; thematic analysis

Medical school in Japan

25 semistructured interviews with medical students, informal interviews with academic faculty, field notes; thematic analysis

Four clinical programmes affiliated with an urban academic medical centre
40 semistructured interviews with community-dwelling older adults; qualitative content analysis
Qualitative research interviews unfold as an interviewer asks questions of the interviewee in order to gather subjective information about a particular topic or experience. Though the definitions and purposes of qualitative research interviews vary slightly in the literature, there is common emphasis on the experiences of interviewees and the ways in which the interviewee perceives the world (see table 2 for summary of definitions from seminal texts).

The most common type of interview used in qualitative research and the healthcare context is semistructured interview. ${ }^{8}$ Figure 1 highlights the key features of this data collection method, which is guided by a list of topics or questions with follow-up questions, probes and comments. Typically, the sequencing and wording of the questions are modified by the interviewer to best fit the interviewee and interview context. Semistructured interviews can be conducted in multiple ways (ie, face to face, telephone, text/email, individual, group, brief, in-depth), each of which have advantages and disadvantages. We will focus on the most common form of semistructured interviews within qualitative research-individual, face-to-face, in-depth interviews.

\section{Purpose of semistructured interviews}

The overall purpose of using semistructured interviews for data collection is to gather information from key informants who have personal experiences, attitudes, perceptions and beliefs related to the topic of interest. Researchers can use semistructured interviews to collect new, exploratory data related to a research topic, triangulate other data sources or validate findings through member checking (respondent feedback about research results). ${ }^{9}$ If using a mixed methods approach, semistructured interviews can also be used in a qualitative phase to explore new concepts to generate hypotheses or explain results from a quantitative phase that tests hypotheses. Semistructured interviews are an effective method for data collection when the researcher wants: (1) to collect qualitative, open-ended data; (2) to explore participant 
Table 2 Definitions of qualitative interviews

\begin{tabular}{|c|c|c|}
\hline Authors & Definition & Purpose \\
\hline DiCicco-Bloom and Crabtree ${ }^{10}$ & $\begin{array}{l}\text { Semistructured interviews are 'organized } \\
\text { around a set of predetermined open-ended } \\
\text { questions, with other questions emerging } \\
\text { from the dialogue between interviewer and } \\
\text { interviewee/s' (2006, p 315) }\end{array}$ & $\begin{array}{l}\text { 'To contribute to a body of knowledge that } \\
\text { is conceptual and theoretical and is based } \\
\text { on the meanings that life experiences hold } \\
\text { for the interviewees' (2006, p 314) }\end{array}$ \\
\hline Hatch $^{12}$ & $\begin{array}{l}\text { 'special kinds of conversations or speech } \\
\text { events that are used by researchers to explore } \\
\text { informants' experiences and interpretations' } \\
\text { (2002, p. 91) }\end{array}$ & $\begin{array}{l}\text { 'To uncover the meaning structures } \\
\text { that participants use to organize their } \\
\text { experiences and make sense of their } \\
\text { worlds' (2002, p 91) }\end{array}$ \\
\hline Kvale $^{7}$ & $\begin{array}{l}\text { 'attempts to understand the world from the } \\
\text { subjects' point of view, to unfold the meaning } \\
\text { of peoples' experiences, to uncover their lived } \\
\text { world prior to scientific explanations' (1996, p } \\
\text { 1) }\end{array}$ & $\begin{array}{l}\text { 'To gather descriptions of the life- } \\
\text { world of the interviewee with respect } \\
\text { to interpretation of the meaning of the } \\
\text { described phenomena' (1983, p 174) }\end{array}$ \\
\hline
\end{tabular}

thoughts, feelings and beliefs about a particular topic; and (3) to delve deeply into personal and sometimes sensitive issues.

\section{Designing and conducting semistructured interviews}

In the following section, we provide recommendations for the steps required to carefully design and conduct semistructured interviews with emphasis on applications in family medicine and primary care research (see table 3).

Steps for designing and conducting semistructured interviews Step 1: determining the purpose and scope of the study

The purpose of the study is the primary objective of your project and may be based on an anecdotal experience, a review of the literature or previous research finding. The purpose is developed in response to an identified gap or problem that needs to be addressed.

Research questions are the driving force of a study because they are associated with every other aspect of the design. They should be succinct and clearly indicate that you are using a qualitative approach. Qualitative research questions typically start with 'What', 'How' or 'Why' and focus on the exploration of a single concept based on participant perspectives. ${ }^{10}$

$$
\begin{aligned}
& \text { Key characteristics of semistructured interviews } \\
& \checkmark \text { Loose, flexible structure } \\
& \checkmark \text { Iterative } \\
& \checkmark \text { Groups or individual participants } \\
& \checkmark \text { Scheduled in advance } \\
& \checkmark \text { Gathers information from key informants who can inform the topic } \\
& \checkmark \text { Insight into participant perspectives } \\
& \checkmark \text { Deep exploration of participant thoughts and experiences } \\
& \checkmark \text { Often the sole data source for a qualitative study }
\end{aligned}
$$

Figure 1 Key characteristics of semistructured interviews.

\section{Step 2: identifying participants}

After deciding on the purpose of the study and research question(s), the next step is to determine who will provide the best information to answer the research question. Good interviewees are those who are available, willing to be interviewed and have lived experiences and knowledge about the topic of interest. ${ }^{11} 12$ Working with gatekeepers or informants to get access to potential participants can be extremely helpful as they are trusted sources that control access to the target sample.

Sampling strategies are influenced by the research question and the purpose of the study. Unlike quantitative studies, statistical representativeness is not the goal of qualitative research. There is no calculation of statistical power and the goal is not a large sample size. Instead, qualitative approaches seek an in-depth and detailed understanding and typically use purposeful sampling. See the study of Hatch for a summary of various types

Table 3 Steps to designing and conducting semistructured interviews

\begin{tabular}{cl}
\hline Step & Task \\
\hline 1 & Determining the purpose and scope of the study \\
\hline 2 & Identifying participants \\
3 & Considering ethical issues \\
\hline 4 & Planning logistical aspects \\
\hline 5 & Developing the interview guide \\
\hline 6 & Establishing trust and rapport \\
\hline 7 & Conducting the interview \\
\hline 8 & Memoing and reflection \\
\hline 9 & Analysing the data \\
\hline 10 & Demonstrating the trustworthiness of the research \\
\hline 11 & Presenting findings in a paper or report \\
\hline
\end{tabular}


of purposeful sampling that can be used for interview studies. ${ }^{12}$

'How many participants are needed?' The most common answer is, 'it depends'-it depends on the purpose of the study, what kind of study is planned and what questions the study is trying to answer. ${ }^{12-14}$ One common standard in qualitative sample sizes is reaching thematic saturation, which refers to the point at which no new thematic information is gathered from participants. Malterud and colleagues discuss the concept of information power, or a qualitative equivalent to statistical power, to determine how many interviews should be collected in a study. They suggest that the size of a sample should depend on the aim, homogeneity of the sample, theory, interview quality and analytic strategy. ${ }^{14}$

\section{Step 3: considering ethical issues}

An ethical attitude should be present from the very beginning of the research project even before you decide who to interview. ${ }^{15}$ This ethical attitude should incorporate respect, sensitivity and tact towards participants throughout the research process. Because semistructured interviewing often requires the participant to reveal sensitive and personal information directly to the interviewer, it is important to consider the power imbalance between the researcher and the participant. In healthcare settings, the interviewer or researcher may be a part of the patient's healthcare team or have contact with the healthcare team. The researchers should ensure the interviewee that their participation and answers will not influence the care they receive or their relationship with their providers. Other issues to consider include: reducing the risk of harm; protecting the interviewee's information; adequately informing interviewees about the study purpose and format; and reducing the risk of exploitation. $^{10}$

\section{Step 4: planning logistical aspects}

Careful planning particularly around the technical aspects of interviews can be the difference between a great interview and a not so great interview. During the preparation phase, the researcher will need to plan and make decisions about the best ways to contact potential interviewees, obtain informed consent, arrange interview times and locations convenient for both participant and researcher, and test recording equipment. Although many experienced researchers have found themselves conducting interviews in less than ideal locations, the interview location should avoid (or at least minimise) interruptions and be appropriate for the interview (quiet, private and able to get a clear recording). ${ }^{16}$ For some research projects, the participants' homes may make sense as the best interview location. ${ }^{16}$

Initial contacts can be made through telephone or email and followed up with more details so the individual can make an informed decision about whether they wish to be interviewed. Potential participants should know what to expect in terms of length of time, purpose of the
Table 4 Suggestions for successful audio recording of interviews

\begin{tabular}{|c|c|}
\hline Component & Suggestions \\
\hline Clarity & $\begin{array}{l}\text { Audio-recording equipment should } \\
\text { clearly capture the interview so that both } \\
\text { interviewer's and interviewee's voices } \\
\text { are easily heard for transcription. Many } \\
\text { interviewers use small battery-powered } \\
\text { recorders but sometimes the microphones } \\
\text { do not work well. }\end{array}$ \\
\hline Reliable & $\begin{array}{l}\text { Audio-recording equipment needs to be } \\
\text { reliable and easy to use. Increasingly, } \\
\text { researchers are using their smartphones to } \\
\text { record interviews. }\end{array}$ \\
\hline Familiarity & $\begin{array}{l}\text { Whatever kind of recording equipment } \\
\text { is used, the researcher needs to be } \\
\text { familiar with it and should test it at the } \\
\text { interview location before starting the actual } \\
\text { interview-you do not want to be fumbling } \\
\text { with technology during the interview. }\end{array}$ \\
\hline Backup & $\begin{array}{l}\text { If you are the sole interviewer and do not } \\
\text { have an additional person taking notes, we } \\
\text { recommend having two recording devices } \\
\text { for each interview in case one device fails } \\
\text { or runs out of batteries. Make sure to bring } \\
\text { extra batteries. }\end{array}$ \\
\hline Note-taking & $\begin{array}{l}\text { Some researchers recommend taking } \\
\text { notes or having a partner take notes during } \\
\text { the interviews in addition to the audio } \\
\text { recording. Taking notes can ensure that all } \\
\text { interview questions have been answered, } \\
\text { guide follow-up questions so that the } \\
\text { interview can flow from the interviewee's } \\
\text { lead and serve as a backup in the case of } \\
\text { malfunctioning recorders. }\end{array}$ \\
\hline
\end{tabular}

study, why they have been selected and who will be there. In addition, participants should be informed that they can refuse to answer questions or can withdraw from the study at any time, including during the interview itself.

Audio recording the interview is recommended so that the interviewer can concentrate on the interview and build rapport rather than being distracted with extensive note taking ${ }^{16}$ (see table 4 for audio-recording tips). Participants should be informed that audio recording is used for data collection and that they can refuse to be audio recorded should they prefer.

Most researchers will want to have interviews transcribed verbatim from the audio recording. This allows you to refer to the exact words of participants during the analysis. Although it is possible to conduct analyses from the audio recordings themselves or from notes, it is not ideal. However, transcription can be extremely time consuming and, if not done yourself, can be costly.

In the planning phase of research, you will want to consider whether qualitative research software (eg, NVivo, ATLAS.ti, MAXQDA, Dedoose, and so on) will be used to assist with organising, managing and analysis. While these 
Table 5 Questions and prompts in semistructured interviewing

\begin{tabular}{|c|c|c|c|}
\hline Type of question & Definition & Purpose & Example \\
\hline Grand tour & $\begin{array}{l}\text { General question related to the } \\
\text { content of the overall research } \\
\text { question, which participant knows a } \\
\text { lot about }\end{array}$ & $\begin{array}{l}\text { Initiate the interview } \\
\text { Help participant to start talking } \\
\text { about their experience }\end{array}$ & $\begin{array}{l}\text { How has your pregnancy been so } \\
\text { far? }\end{array}$ \\
\hline Core questions & $\begin{array}{l}\text { Five to } 10 \text { questions that directly } \\
\text { relate to the information the } \\
\text { researcher wants to know }\end{array}$ & $\begin{array}{l}\text { Answer the research question(s) } \\
\text { Help participant talk openly about } \\
\text { the topic in an exploratory way } \\
\text { Typically asked of all participants }\end{array}$ & $\begin{array}{l}\text { What do you think pregnant women } \\
\text { should do for exercise during } \\
\text { pregnancy? }\end{array}$ \\
\hline $\begin{array}{l}\text { Unplanned follow-up } \\
\text { questions }\end{array}$ & $\begin{array}{l}\text { Questions that arise during the } \\
\text { interview based on participant } \\
\text { responses }\end{array}$ & $\begin{array}{l}\text { Answer particular aspects of the } \\
\text { participant response } \\
\text { Obtain greater detail about } \\
\text { responses } \\
\text { Asked depending on participant } \\
\text { responses }\end{array}$ & $\begin{array}{l}\text { You mentioned that you were feeling } \\
\text { lonely and didn't have the energy to } \\
\text { exercise during pregnancy. Can you } \\
\text { tell me more about that? }\end{array}$ \\
\hline
\end{tabular}

tools are helpful in the management of qualitative data, it is important to consider your research budget, the cost of the software and the learning curve associated with using a new system.

\section{Step 5: developing the interview guide}

Semistructured interviews include a short list of 'guiding' questions that are supplemented by follow-up and probing questions that are dependent on the interviewee's responses. ${ }^{817}$ All questions should be open ended, neutral, clear and avoid leading language. In addition, questions should use familiar language and avoid jargon.

Most interviews will start with an easy, context-setting question before moving to more difficult or in-depth questions. ${ }^{17}$ Table 5 gives details of the types of guiding questions including 'grand tour' questions, ${ }^{18}$ core questions and planned and unplanned follow-up questions.

To illustrate, online supplementary appendix A presents a sample interview guide from our study of weight gain during pregnancy among young women. We start with the prompt, 'Tell me about how your pregnancy has been so far' to initiate conversation about their thoughts and feelings during pregnancy. The subsequent questions will elicit responses to help answer our research question about young women's perspectives related to weight gain during pregnancy.

After developing the guiding questions, it is important to pilot test the interview. Having a good sense of the guide helps you to pace the interview (and not run out of time), use a conversational tone and make necessary adjustments to the questions.

Like all qualitative research, interviewing is iterative in nature-data collection and analysis occur simultaneously, which may result in changes to the guiding questions as the study progresses. Questions that are not effective may be replaced with other questions and additional probes can be added to explore new topics that are introduced by participants in previous interviews. ${ }^{10}$

\section{Step 6: establishing trust and rapport}

Interviews are a special form of relationship, where the interviewer and interviewee converse about important and often personal topics. The interviewer must build rapport quickly by listening attentively and respectfully to the information shared by the interviewee. ${ }^{19}$ As the interview progresses, the interviewer must continue to demonstrate respect, encourage the interviewee to share their perspectives and acknowledge the sensitive nature of the conversation. $^{20}$

To establish rapport, it is important to be authentic and open to the interviewee's point of view. It is possible that the participants you recruit for your study will have preconceived notions about research, which may include mistrust. As a result, it is important to describe why you are conducting the research and how their participation is meaningful. In an interview relationship, the interviewee is the expert and should be treated as such-you are relying on the interviewee to enhance your understanding and add to your research. Small behaviours that can enhance rapport include: dressing professionally but not overly formal; avoiding jargon or slang; and using a normal conversational tone. Because interviewees will be discussing their experience, having some awareness of contextual or cultural factors that may influence their perspectives may be helpful as background knowledge.

\section{Step 7: conducting the interview}

\section{Location and set-up}

The interview should have already been scheduled at a convenient time and location for the interviewee. The location should be private, ideally with a closed door, rather than a public place. It is helpful if there is a room 
where you can speak privately without interruption, and where it is quiet enough to hear and audio record the interview. Within the interview space, Josselson ${ }^{15}$ suggests an arrangement with a comfortable distance between the interviewer and interviewee with a low table in between for the recorder and any materials (consent forms, questionnaires, water, and so on).

\section{Beginning the interview}

Many interviewers start with chatting to break the ice and attempt to establish commonalities, rapport and trust. Most interviews will need to begin with a brief explanation of the research study, consent/assent procedures, rationale for talking to that particular interviewee and description of the interview format and agenda. ${ }^{11}$ It can also be helpful if the interviewer shares a little about who they are and why they are interested in the topic. The recording equipment should have already been tested thoroughly but interviewers may want to double-check that the audio equipment is working and remind participants about the reason for recording.

\section{Interviewer stance}

During the interview, the interviewer should adopt a friendly and non-judgemental attitude. You will want to maintain a warm and conversational tone, rather than a rote, question-answer approach. It is important to recognise the potential power differential as a researcher. Conveying a sense of being in the interview together and that you as the interviewer are a person just like the interviewee can help ease any discomfort. ${ }^{15}$

\section{Active listening}

During a face-to-face interview, there is an opportunity to observe social and non-verbal cues of the interviewee. These cues may come in the form of voice, body language, gestures and intonation, and can supplement the interviewee's verbal response and can give clues to the interviewer about the process of the interview. ${ }^{21}$ Listening is the key to successful interviewing. ${ }^{22}$ Listening should be 'attentive, empathic, nonjudgmental, listening in order to invite, and engender talk ${ }^{15}{ }^{15}$ (p 66). Silence, nods, smiles and utterances can also encourage further elaboration from the interviewee.

\section{Continuing the interview}

As the interview progresses, the interviewer can repeat the words used by the interviewee, use planned and unplanned follow-up questions that invite further clarification, exploration or elaboration. As DiCicco-Bloom and Crabtree ${ }^{10}$ explain: 'Throughout the interview, the goal of the interviewer is to encourage the interviewee to share as much information as possible, unselfconsciously and in his or her own words' ( $p$ 317). Some interviewees are more forthcoming and will offer many details of their experiences without much probing required. Others will require prompting and follow-up to elicit sufficient detail.

As a result, follow-up questions are equally important to the core questions in a semistructured interview.
Table 6 Probing techniques for semistructured interviews (modified from Bernard $^{30}$ )

\begin{tabular}{|c|c|c|}
\hline $\begin{array}{l}\text { Probing } \\
\text { technique }\end{array}$ & Description & Example \\
\hline Wait time & $\begin{array}{l}\text { Interviewer remains } \\
\text { silent after asking } \\
\text { a question. } \\
\text { This allows the } \\
\text { interviewee to } \\
\text { think about their } \\
\text { response and } \\
\text { often encourages } \\
\text { the interviewee to } \\
\text { speak. }\end{array}$ & $\begin{array}{l}\text { What do you think } \\
\text { pregnant women } \\
\text { should do for } \\
\text { exercise during } \\
\text { pregnancy? (Wait, } \\
\text { do not respond } \\
\text { with additional } \\
\text { questioning until } \\
\text { participant speaks) }\end{array}$ \\
\hline Echo & $\begin{array}{l}\text { Interviewer repeats } \\
\text { or summarises the } \\
\text { participant's words, } \\
\text { encouraging them } \\
\text { to go into more } \\
\text { detail. }\end{array}$ & $\begin{array}{l}\text { Right, so it was } \\
\text { hard to exercise } \\
\text { after working all } \\
\text { day. }\end{array}$ \\
\hline Verbal agreement & $\begin{array}{l}\text { Interviewer uses } \\
\text { affirming words } \\
\text { to encourage the } \\
\text { interviewee to } \\
\text { continue speaking. }\end{array}$ & $\begin{array}{l}\text { Yes... } \\
\text { Okay... }\end{array}$ \\
\hline Expansion & $\begin{array}{l}\text { Interviewer asks } \\
\text { participant to } \\
\text { elaborate on a } \\
\text { particular response. }\end{array}$ & $\begin{array}{l}\text { Tell me more. } \\
\text { Give me an } \\
\text { example of that. } \\
\text { Can you describe } \\
\text { that? }\end{array}$ \\
\hline Explanation & $\begin{array}{l}\text { Interviewer asks } \\
\text { participant to } \\
\text { clarify a specific } \\
\text { comment. }\end{array}$ & $\begin{array}{l}\text { Tell me what you } \\
\text { mean when you } \\
\text { say exercise is } \\
\text { 'disruptive'? }\end{array}$ \\
\hline Leading & $\begin{array}{l}\text { Interviewer asks } \\
\text { interviewee to } \\
\text { explain their } \\
\text { reasoning. }\end{array}$ & $\begin{array}{l}\text { You said that you } \\
\text { decided to only } \\
\text { exercise after the } \\
\text { baby is born. Tell } \\
\text { me how you came } \\
\text { to that decision. }\end{array}$ \\
\hline
\end{tabular}

Prompts encourage people to continue talking and they can elicit more details needed to understand the topic. Examples of verbal probes are repeating the participant's words, summarising the main idea or expressing interest with verbal agreement. ${ }^{811}$ See table 6 for probing techniques and example probes we have used in our own interviewing.

\section{Step 8: memoing and reflection}

After an interview, it is essential for the interviewer to begin to reflect on both the process and the content of the interview. During the actual interview, it can be difficult to take notes or begin reflecting. Even if you think you will remember a particular moment, you likely will not be able to recall each moment with sufficient detail. Therefore, interviewers should always record memosnotes about what you are learning from the data. ${ }^{23} 24$ There are different approaches to recording memos: you 
can reflect on several specific ideas, or create a running list of thoughts. Memos are also useful for improving the quality of subsequent interviews.

\section{Step 9: analysing the data}

The data analysis strategy should also be developed during planning stages because analysis occurs concurrently with data collection. ${ }^{25}$ The researcher will take notes, modify the data collection procedures and write reflective memos throughout the data collection process. This begins the process of data analysis.

The data analysis strategy used in your study will depend on your research question and qualitative design-see the study of Creswell for an overview of major qualitative approaches. ${ }^{26}$ The general process for analysing and interpreting most interviews involves reviewing the data (in the form of transcripts, audio recordings or detailed notes), applying descriptive codes to the data and condensing and categorising codes to look for patterns. ${ }^{24} 27$ These patterns can exist within a single interview or across multiple interviews depending on the research question and design. Qualitative computer software programs can be used to help organise and manage interview data.

\section{Step 10: demonstrating the trustworthiness of the research}

Similar to validity and reliability, qualitative research can be assessed on trustworthiness. ${ }^{928}$ There are several criteria used to establish trustworthiness: credibility (whether the findings accurately and fairly represent the data), transferability (whether the findings can be applied to other settings and contexts), confirmability (whether the findings are biased by the researcher) and dependability (whether the findings are consistent and sustainable over time).

\section{Step 11: presenting findings in a paper or report}

When presenting the results of interview analysis, researchers will often report themes or narratives that describe the broad range of experiences evidenced in the data. This involves providing an in-depth description of participant perspectives and being sure to include multiple perspectives. ${ }^{12}$ In interview research, the participant words are your data. Presenting findings in a report requires the integration of quotes into a more traditional written format.

\section{CONCLUSIONS}

Though semistructured interviews are often an effective way to collect open-ended data, there are some disadvantages as well. One common problem with interviewing is that not all interviewees make great participants. ${ }^{1229}$ Some individuals are hard to engage in conversation or may be reluctant to share about sensitive or personal topics. Difficulty interviewing some participants can affect experienced and novice interviewers. Some common problems include not doing a good job of probing or asking for follow-up questions, failure to actively listen, not having a well-developed interview guide with open-ended questions and asking questions in an insensitive way. Outside of pitfalls during the actual interview, other problems with semistructured interviewing may be underestimating the resources required to recruit participants, interview, transcribe and analyse the data.

Despite their limitations, semistructured interviews can be a productive way to collect open-ended data from participants. In our research, we have interviewed children and adolescents about their stress experiences and coping behaviours, young women about their thoughts and behaviours during pregnancy, practitioners about the care they provide to patients and countless other key informants about health-related topics. Because the intent is to understand participant experiences, the possible research topics are endless.

Due to the close relationships family physicians have with their patients, the unique settings in which they work, and in their advocacy, semistructured interviews are an attractive approach for family medicine researchers, even if working in a setting with limited research resources. When seeking to balance both the relational focus of interviewing and the necessary rigour of research, we recommend: prioritising listening over talking; using clear language and avoiding jargon; and deeply engaging in the interview process by actively listening, expressing empathy, demonstrating openness to the participant's worldview and thanking the participant for helping you to understand their experience.

\section{FURTHER READING}

- Edwards R, \& Holland J. (2013). What is qualitative interviewing?: A\&C Black.

- Josselson R. Interviewing for qualitative inquiry: A relational approach. Guilford Press, 2013.

- Kvale S. InterViews: An Introduction to Qualitative Research Interviewing. SAGE, London, 1996.

- Pope C, \& Mays N. (Eds). (2006). Qualitative research in health care.

Contributors Both authors contributed equally to this work.

Funding The authors have not declared a specific grant for this research from any funding agency in the public, commercial or not-for-profit sectors.

Competing interests None declared.

Patient consent for publication Not required.

Provenance and peer review Not commissioned; internally peer reviewed.

Open access This is an open access article distributed in accordance with the Creative Commons Attribution Non Commercial (CC BY-NC 4.0) license, which permits others to distribute, remix, adapt, build upon this work non-commercially, and license their derivative works on different terms, provided the original work is properly cited, appropriate credit is given, any changes made indicated, and the use is non-commercial. See: http://creativecommons.org/licenses/by-nc/4.0

\section{REFERENCES}

1. Chang T, Llanes M, Gold KJ, et al. Perspectives about and approaches to weight gain in pregnancy: a qualitative study of physicians and nurse midwives. BMC Pregnancy Childbirth 2013;13. 
2. Croxson $\mathrm{CH}$, Ashdown HF, Hobbs FR. GPs' perceptions of workload in England: a qualitative interview study. Br J Gen Pract 2017;67:e138-47.

3. DeJonckheere $\mathrm{M}$, Robinson $\mathrm{CH}$, Evans L, et al. Designing for clinical change: creating an intervention to implement new statin guidelines in a primary care clinic. JMIR Hum Factors 2018;5.

4. Griffiths F, Lowe P, Boardman F, et al. Becoming pregnant: exploring the perspectives of women living with diabetes. Br J Gen Pract 2008;58:184-90.

5. Saigal P, Takemura Y, Nishiue T, et al. Factors considered by medical students when Formulating their specialty preferences in Japan: findings from a qualitative study. BMC Med Educ 2007;7.

6. Schoenborn NL, Lee K, Pollack CE, et al. Older adults' preferences for when and how to discuss life expectancy in primary care. $\mathrm{J} A m$ Board Fam Med 2017;30:813-5.

7. Kvale S. Interviews. Thousand Oaks: SAGE Publications, 1996.

8. Kallio H, Pietilä A-M, Johnson M, et al. Systematic methodological review: developing a framework for a qualitative semi-structured interview guide. J Adv Nurs 2016;72:2954-65.

9. Lincoln YS, Guba EG. Naturalistic inquiry. 75. SAGE, 1985.

10. DiCicco-Bloom B, Crabtree BF. The qualitative research interview. Med Educ 2006;40:314-21.

11. Whiting LS. Semi-structured interviews: guidance for novice researchers. Nurs Stand 2008;22:35-40.

12. Hatch JA. Doing qualitative research in education settings. Suny Press, 2002.

13. Guest G, Bunce A, Johnson L. How many interviews are enough? An experiment with data saturation and variability. Field methods 2006;18:59-82.

14. Malterud K, Siersma VD, Guassora AD. Sample size in qualitative interview studies: guided by information power. Qualitativehealth research 2016;26:1753-60.

15. Josselson R. Interviewing for qualitative inquiry: A relational approach. Guilford Press, 2013.
16. Edwards R, Holland J. What is qualitative interviewing? A\&C Black, 2013.

17. Britten N. Qualitative interviews. Qualitative research in health care, 2006: 12-20.

18. Spradley JP. The ethnographic interview. 1979. Waveland Press, 2016.

19. Spradley JP. The ethnographic interview. Waveland Press, 2016.

20. Shank GD. Qualitative research: a personal skills approach. Pearson Merrill Prentice Hall, 2006.

21. Opdenakker R. Advantages and disadvantages of four interview techniques in qualitative research. Paper presented at: Forum Qualitative Sozialforschung/Forum: Qualitative Social Research, 2006.

22. Anderson K, Jack DC. Learning to listen: interview techniques and analyses, 1991: 11-26.

23. Miles MB, Huberman AM. Qualitative data analysis: an expanded sourcebook. Thousand Oaks: SAGE Publications, 1994.

24. Miles MB, Huberman AM, Saldana J. Qualitative data analysis. SAGE, 2013.

25. Babchuk WA. Fundamentals of qualitative analysis in family medicine. Family Medicine and Community Health, 2019.

26. Creswell JW. Qualitative inquiry and research design: choosing among five approaches. Los Angeles: SAGE Publications, 2013.

27. Forman J, Damschroder L. Qualitative content analysis. In: Empirical methods for bioethics: A primer. Emerald Group Publishing Limited, 2007: 39-62.

28. Shenton AK. Strategies for ensuring trustworthiness in qualitative research projects. Education for Information 2004;22:63-75.

29. Watkins DC. Qualitative research: the importance of conducting research that doesn't "count". Health Promot Pract 2012;13:153-8.

30. Bernard HR. Social research methods: quantitative and qualitative approaches. SAGE, 2000. 